\title{
Trick or treat? - when children with childhood food allergies lead parents into unhealthy food choices
}

\author{
Ali B. Mahmoud ${ }^{1 *}$ (D), Dieu Hack-Polay ${ }^{2,3}$, Leonora Fuxman ${ }^{4}$, Dina Naquiallah ${ }^{5}$ and Nicholas Grigoriou ${ }^{6}$
}

\begin{abstract}
Background: This study examines the relationships between childhood food allergy and parental unhealthy food choices for their children across attitudes towards childhood obesity as mediators and parental gender, income and education as potential moderators.

Methods: We surveyed parents with at least one child between the ages of 6 and 12 living in Canada and the United States. We received 483 valid responses that were analysed using structural equation modelling approach with bootstrapping to test the hypothetical path model and its invariance across the moderators.

Results: The analysis revealed that pressure to eat fully mediated the effects of childhood food allergy and restriction on parental unhealthy food choices for their children. Finally, we found that parental gender moderated the relationship between childhood food allergy and the pressure to eat.

Conclusions: The paper contributes to the literature on food allergies among children and the marginalisation of families with allergies. Our explorative model is a first of its kind and offers a fresh perspective on complex relationships between variables under consideration. Although our data collection took place prior to Covid-19 outbreak, this paper bears yet particular significance as it casts light on how families with allergies should be part of the priority groups to have access to food supply during crisis periods.
\end{abstract}

Keywords: Childhood obesity, Food allergy, Parenting, Attitudes, Gender, Healthy eating, COVID-19

\section{Background}

Various factors determine the choice of food. Although a more substantial interest is shown in understanding and determining environmental, social and cultural factors that influence the choice of food, an assessment of the influence of parents in early years and the association with the nutritional health of children are vital. Family eating behaviours, social status and the structure of family alongside cultural heritage are among the factors that influence food choices in a family setting [1]. During the last decade, socio-economic changes

\footnotetext{
* Correspondence: elguitarrista@live.com

${ }^{1}$ University of Wales Trinity Saint David, London, UK

Full list of author information is available at the end of the article
}

profoundly influenced family diets and consequently, food choices for children, which are often high in fat and sugar. The decreased time spent on preparing healthy meals [2,3] and the increased availability as well as affordability of highly processed foods has contributed to the popularity of convenient but unhealthy alternative foods. That has led to the growing imbalance in the children's diets, which now contain more calories, fat and sodium than the right proportion advised for their age group [4], thus causing concerns about the growing statistics on childhood obesity. Latest data from the 'Canadian Community Health Survey' (StatCan) shows steady yearly increases in the percentage of adolescents who are deemed overweight or obese from 2005 to 2018

C C The Author(s). 2020 Open Access This article is licensed under a Creative Commons Attribution 4.0 International License, which permits use, sharing, adaptation, distribution and reproduction in any medium or format, as long as you give appropriate credit to the original author(s) and the source, provide a link to the Creative Commons licence, and indicate if changes were made. The images or other third party material in this article are included in the article's Creative Commons licence, unless indicated otherwise in a credit line to the material. If material is not included in the article's Creative Commons licence and your intended use is not permitted by statutory regulation or exceeds the permitted use, you will need to obtain permission directly from the copyright holder. To view a copy of this licence, visit http://creativecommons.org/licenses/by/4.0/ The Creative Commons Public Domain Dedication waiver (http://creativecommons.org/publicdomain/zero/1.0/) applies to the data made available in this article, unless otherwise stated in a credit line to the data. 
based on the Body Mass Index (BMI) [5], reaching 28\% in 2018 [5], although showing a somewhat decreased percentage of $23.7 \%$ in 2018. Further, in the United States, recent numbers show that childhood obesity has affected 14 million children and adolescents with an almost 19\% prevalence [6]. The global overweight and obesity prevalence for children is predicted to reach $9 \%$ [7], i.e., 60 million children in 2020.

As a primary cause of increased obesity rates, food decisions are also seen to be linked to other health issues affecting both individuals and society as a whole [8]. Additionally, child food allergy alongside parental attitudes towards childhood obesity has been considered critical factors when parental food choices for children are debated (e.g., [9]). There has been no shortage of research on the causes of childhood obesity and children's eating habits [10], with oftentimes contradictory outcomes. It has been found, for example, that restricting children's access to snacks makes restricted foods more attractive [11], hence promoting unhealthy food choices. In contrast, exercising no control over food selections has been shown to contribute to the development of weight excess [12]. Child's predisposition to food allergies further complicates our understanding of parental food choices for their children.

This study attempts to clarify further complex relationships in parental food selection decisions for their children who experience food allergies, weighting in parental behavioural strategies towards food choices for their kids (such as pressure to eat and restriction). The study is particularly relevant in the current period of the coronavirus (covid-19) outbreak which has led to empty shelves in shops in the United States and Canada for food suitable for allergy sufferers. With an increase in panic buying, families that have children with allergy issues struggle to source essential supplies [13]. This issue suggests that parents of children with allergies are marginalised [14, 15]. The lockdown of whole countries such as the USA and Canada meant that millions of people have had to be in isolation in their homes, which causes a significant number of people to put on weight $[2,16-18]$. We develop and test a novel path model that links child food allergy to parental unhealthy food choices for their children via parental attitudes towards childhood obesity. We also examine the moderating effects of a parent's gender, education, and income [19] on the path model by utilising a structural equation modelling approach and bootstrapping. Our explorative model is a first of its kind to shed more light into complex relationships between variables under consideration.

\section{Theoretical foundations and hypotheses}

Food allergy refers to abnormal reactions to a food protein and is the most common source of critical allergic reactions that pose life-threatening complications [20]. Anaphylaxis is a common form of food allergy. Food allergy is deemed a widespread chronic condition with an expected prevalence of 4-9\% in children [20]. About $8 \%$ of North American children suffer from a reported food allergy [14, 21, 22]. It is projected that food allergies cost the US economy about USD 25 billion per year, ranging from loss of family workdays, to direct and indirect costs of medical appointments [14, 21, 23]. Food allergies are unique because till recently; there were no pharmaceutical interventions to prevent allergic reactions [24]. As a result, the management of children's dietary intake through strict avoidance of certain food types remains critical [25]. However, there is now an FDA-approved paediatric peanut allergen immunotherapy "Palforzia" and many food allergen immunotherapies (i.e. oral, epicutaneous, sublingual) that are currently being tested and have been found to be safe/efficacious in phase I-II studies [26]. If these results are repeated in phase III trials, they will constitute a significant breakthrough in food allergy.

Childhood allergy to food is increasingly widespread. It is often accompanied by a heightened level of parental worry about caring for such children [27] due to the need to set and follow dietary restrictions which in turn can significantly influence family living standards, including their social activities [28]. The food-allergyrelated fears, coupled with a continued need for food choice monitoring and possible personal activity constraints, can have psychological implications for the people concerned and their caregivers. Notably, it has been shown that parents of food-allergic children are more anxious than parents of children with other health problems [29]. The occurrence of allergy amongst children limits the consumption of nutritional food often without adequate nutrient replacement [30]. In addition to dietary challenges, children with food intolerances also face other issues such as anxiety, food aversion and refusal, which increases the risk of poor nutrition, affecting parental guidance and parental behaviour towards food decisions [31]. Furthermore, children's food allergies have been found to have a significant effect on parent's in-home meal preparation [32]. Additionally, research suggests a positive association between increased body weight and predisposition to food allergies [33], while also links parental perceptions of food allergies to their children' diet [34] which collectively, provide additional insights into the role food allergies play in the food selection process.

In addition to the genetic aspects connected with obesity, a number of behavioural obesity risk factors, such as an unhealthy diet with excessive sodium and fat consumption coupled with the absence of physical exercise have also been highlighted in previous research [35]. 
Such behavioural obesity risk factors are directly influenced by social and environmental components at home, school, and other social circles [36]. In the context of the ongoing pandemic with covid-19, more evidence is emerging to support the link between children not attending school due to the lockdown of many countries and obesity levels in children [16, 37]. However, the existence of the linkage between parental food decisions and the way they impact behavioural obesity risk factors in children have not been studied before, and that is where this research study offers a novel contribution.

The parental pressure put on children to eat reflects the attitudes of the parent towards obesity. Eating pressuring strategies could be seen as either friendly communicative or correctional when parents use them. An example of correctional is when parents engage in bribing children to eat all the food on their plates [38]. Alternatively, as a friendly communicative strategy, parents may attempt to encourage their children to develop good eating habits and share with them directive information that enhance the chances of making healthy food choices [39]. Most childhood obesity prevention programs are school-based, meaning that the primary understanding of nutrition and healthy eating is acquired at school, not at home [40]. As a result, parents who do not know the dietary requirements and nutritional needs of their children, often put pressure on their children to 'clean up their food,' an idea that a meal is not complete unless all food is eaten [40]. Research indicates that eventually, the practice of pressuring kids to eat leads to the development of dislikes for foods that children are told to eat [41]. Such parental eating pressure behaviour primarily links to the cultural beliefs that the absence of hunger and heavier children are associated with a healthier status $[42,43]$. Parental pressure eating behaviour has also been linked to obesity development in an obesogenic environment when food scarcity is present [40]. In this study, the pressure to eat is theorised as a negative concept, that is, pressure to eat presents a risk associated with obesity.

Finally, parental restriction on their children's food intake is another vital variable in our study. According to LC Moore, CV Harris and AS Bradlyn [44], when children are permitted to select their own foods from a variety of both healthy and unhealthy food choices, children typically select unhealthy foods (e.g., high in fat). The Parental restriction is also linked to allergen avoidance for children suffering from a food allergy, but often not replacing eliminated nutrients with proper alternatives [30].

Even worse is the fact that a child is allowed to consume what they like so that children select foods with high levels of sodium, fat and sugar [45]. Some parents believe that they grant their children's wishes for these foods out of love and see them as treats [46]. Some parents are directed to unhealthy food out of sheer ignorance about diet generally [47, 48]. As a result of these constraints, it is believed that $90 \%$ of American families have their children on foods that challenge positive dietary practices that are conducive to good health $[46,47]$. Additionally, JS Savage, JO Fisher and LL Birch believe that the relatively inexpensive cost of energy-dense foods is a crucial factor that lures parents towards such choices [48]. In the current covid-19 pandemic, with the spiralling cost of food generally, millions of poor households in the USA and around the world have turned to 'junk' food for survival. In the period of the pandemic, more than in any other period, economics, thus, dictates what parents treat their children with despite the consequences of unhealthy food.

Recent research has conceptualised childhood food allergy as a moderating variable for a number of unhealthy parental eating behaviours for their children with suggestions that future research conceptualises childhood food allergy as an endogenous variable when investigating unhealthy eating behaviours [8]. Hence, we hypothesise the following relationships between child food allergy, parental unhealthy food choices and obesity attitudes (see Fig. 1):

- Hypothesis 1: Child food allergy predicts parental attitudes towards childhood obesity.

- Hypothesis 2: Child food allergy predicts parental unhealthy food choices for their children.

- Hypothesis 3: Parental attitudes towards childhood obesity predict unhealthy food choices for their children.

Hypothesis 3a: Pressure to eat increases the chances for parental unhealthy food choices for their children.

Hypothesis 3b: Restriction on children's dietary intake lowers the chances for parental unhealthy food choices for their children.

- Hypothesis 4: Parents' gender, education, and income moderate the relationships stated in Hypotheses 1, 2, and 3.

Also, based on the directions of the relationships in Hypotheses 1, 2 and 3 and according to RM Baron and DA Kenny's [49] conceptualisation of the properties of mediators, we will test parental attitudes towards childhood obesity as a potential mediator between childhood food allergy and parental unhealthy food choices.

\section{Methods}

The study took place between September 2017 and $\mathrm{Au}$ gust 2019. We randomly sampled American and Canadian parents of children aged 6-12, approaching them via their schools and social networks. Eight primary schools were 


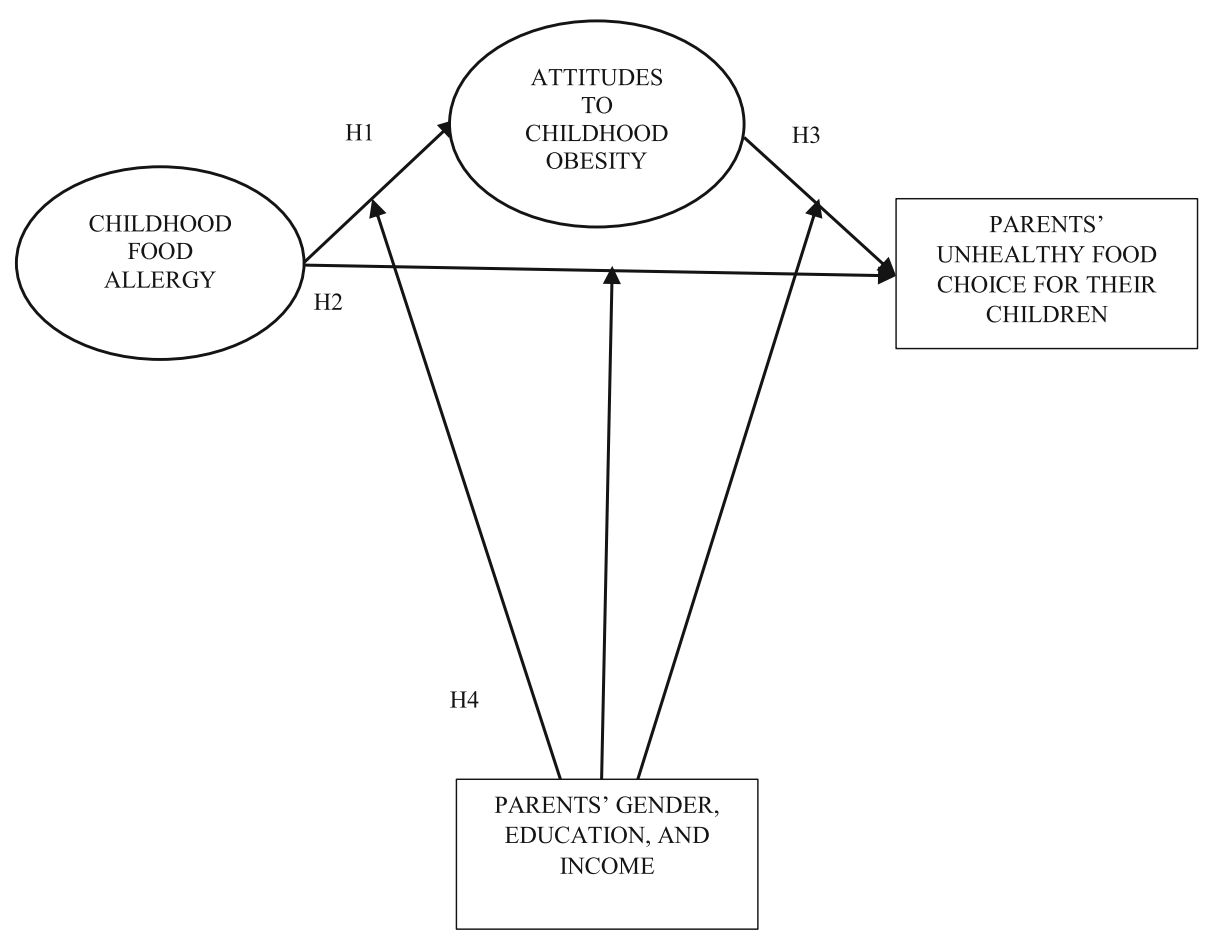

Fig. 1 Hypothetical model

chosen randomly (four schools in Chicago area, US and four schools in a province of Ontario, Canada) where a total of 1000 questionnaires were distributed. To increase the representativeness of our sample, we used a stratified sampling technique. In that regard, fifty questionnaires were allocated to each of the two groups of parents, that is, of students both prone and not prone to food allergies in each school. Proneness to food allergy was determined during an initial phone call with the parents to obtain basic information about the parental history of atopy. The initial phone call also allowed the researchers to gain their prior consent to take part in the study. Two hundred questionnaires were distributed via groups dedicated to child diets on social networks. The survey would not be submitted unless it was fully completed. The entire sampling process yielded 483 complete cases that were used in the analyses. That is, we followed a quantitative method to analyse the data. This consisted primarily of Covariance-based Structural Equation Modelling (CB-SEM) to assess the hypothetical structural model as well as its invariance linked to parents' gender, income, or education.

Our self-administered survey simulated the respondents' decision making when purchasing food at fastfood restaurants affiliated to one of the most valuable fast food brands in the world [50]. We recreated the restaurant's full menu, including nutrition facts for each of the variety of items it serves. We then integrated the menu into our survey and asked participants to order meals for themselves and their child as they normally do when visiting the restaurant. We measured parent's unhealthy food choice for their child as a dichotomous variable [8]. We calculated the variable employing the main nutritional values (i.e., fat as \%DV, sodium and calories) [51] and coded it as 0, which represents 'healthy' choice whilst 1 was assigned for an 'unhealthy' choice [8]. That criterion was used to label choices as either unhealthy when a meal choice would give more than $35 \%$ of total calories from fat, $640 \mathrm{mg}$ of sodium and $600 \mathrm{cal}$, or otherwise as healthy [51]. Child food allergy was assessed using one question: "Is your child allergic to any food?" The participants were asked that question twice and in different places in the questionnaire to double-check that they certainly were aware of their child's food allergy status. We measured restriction and pressure to eat, as attitudinal components towards childhood obesity by employing question items from the 'Child Feeding Questionnaire' (CFQ) [1]. The items were evaluated using a five-point Likert scale, where 5 and 1 representing 'strongly agree' and 'strongly disagree' respectively. Sample items for pressure to eat were "I have to be especially careful to make sure my child eats enough" and "If I did not guide or regulate my child's eating, he/she would eat much less than he/she should." Additionally, representing items for restriction "I have to be sure that my child does not eat too many sweets (candy, ice-cream, cake or pastries)" and "I have to be sure that my child does not eat too many high-fat foods." The factorial dimensionality of parent's attitudes 
towards childhood obesity, comprising of pressure to eat and restriction, was judged to be both internally consistent and valid $\mathrm{AVE}$ pressure-to-eat $=.556 ; \mathrm{CR}$ pressure-to-eat $=.789$; $\mathrm{AVE}$ restriction $=.566 ; \mathrm{CR}$ restriction $=.793, \mathrm{RMESA}=.048<$ $0.08, \quad \mathrm{SRMR}=.062<.08,{ }^{2} / \mathrm{df}=1.63<3, \quad \mathrm{NFI}=.947>.9$, and $\mathrm{CFI}=.979>.9$ [52]. Finally, we conducted Harman's single factor test to assess the common method bias (CMB) [53] for parental attitudes towards childhood obesity. The common factor yielded $26.77 \%$ of the variance, which is far less than $50 \%$; thus, there was no threat to CMB [53]. Amos V. 24 and SPSS V. 26 were used to run the analyses.

\section{Results}

As stated earlier, we received 483 valid responses (57\% were from the US) in the study. Seventy-four per cent were mothers. Most of the respondents had a universitylevel degree, an associate degree or lower (61\%), earning a household income of less than USD 60,000 per year (55\%). Sixty-four per cent of our sample had a tendency to pick unhealthy food options for their children. Only $17 \%$ of the participating parents had a child allergic to some type of food allergy. Based on chi-square values, no associations were found between the sociodemographic variables and parental unhealthy food choices for their children. Employing Cohen's $d$ (for effect size calculation) alongside one-sample t-test that compared mean values for restriction and pressure to eat to the neutral value, i.e., 3 (since those variable were assessed based on 5-point Likert scale), we found that the participants exhibited medium to small positive levels of attitudes regarding both pressure to eat $($ mean $=$
3.16, $\mathrm{SD}=.84, \mathrm{t}=4.10, d f=482, P<.001$, Cohen's $d=$ 20 ) and restriction (mean $=3.51, \mathrm{SD}=.79, \mathrm{t}=14.18, d f=$ 482, $P<.001$, Cohen's $d=.64$ ). Table 1 shows the main demographics, attitudes' descriptives and parental food choices' frequencies broken down by the U.S. vs Canadian samples.

The hypothesised path (see Fig. 1) is assessed first regarding the effects of childhood food allergy on parental unhealthy food choices via pressure to eat, and restriction attitudes using IBM Amos version 25. Key fit indices are utilised to evaluate the validity of $\mathrm{H} 1, \mathrm{H} 2$, and H3. Although some statistics, e.g., ${ }^{2} / \mathrm{df}=2.86<3$, $\mathrm{CFI}=.96>.9, \quad \mathrm{TLI}=.91>.9, \quad \mathrm{SRMR}=.046<.08$, RMSEA $=.062<.08$ demonstrate that the path model is of an adequate fit for our sample data [8], some paths, i.e., child allergy $\rightarrow$ Restriction, child allergy $\rightarrow$ parental unhealthy food choices, and restriction $\rightarrow$ parental unhealthy food choices were non-significant, thus, eliminated and an alternate model was produced (see Fig. 2). As shown in Table 2, the RMSEA of the alternate model dropped to $0.056<.06$, which is an indication of the improved fit. Table 3 demonstrates the testing of the indirect effects with bootstrapping and suggests that pressure to eat fully mediates the paths that link both child food allergy $(\mathrm{B}=.05 ; P<.01)$ and restriction $(\mathrm{B}=-.02 ; P<.01)$ to parental unhealthy food choices for their children. Taking all with the significance and values of estimates shown in Table 2 and Table 3 [8], we come to the conclusion that pressure to eat positively predicts parent's unhealthy food choices for their children. Also, the pressure to eat serves as a mediator to fully transmit the positive indirect effects of childhood food allergy and the

Table 1 Sample description

\begin{tabular}{|c|c|c|c|}
\hline \multirow[t]{2}{*}{ Variable } & \multirow[t]{2}{*}{ Label/Descriptive } & \multicolumn{2}{|l|}{ Country } \\
\hline & & Canada & The U.S. \\
\hline \multirow[t]{2}{*}{ Parental gender } & Male & $34 \%$ & $19 \%$ \\
\hline & Female & $66 \%$ & $81 \%$ \\
\hline \multirow[t]{2}{*}{ Child has food allergy } & Yes & $16 \%$ & $18 \%$ \\
\hline & No & $84 \%$ & $82 \%$ \\
\hline \multirow[t]{2}{*}{ Education level } & Low: < degree level & $25 \%$ & $59 \%$ \\
\hline & High: $\geq$ degree level & $75 \%$ & $41 \%$ \\
\hline \multirow[t]{2}{*}{ Household Income } & Low: $\leq$ USD 60,000/CAD 80,000 & $59 \%$ & $52 \%$ \\
\hline & High: > USD 60,000/CAD 80,000 & $41 \%$ & $48 \%$ \\
\hline \multirow[t]{2}{*}{ Parental food choice } & Unhealthy & $62 \%$ & $66 \%$ \\
\hline & Healthy & $38 \%$ & $34 \%$ \\
\hline \multirow[t]{2}{*}{ Restriction } & Mean & 3.61 & 3.44 \\
\hline & SD & 0.78 & 0.80 \\
\hline \multirow[t]{2}{*}{ Pressure to eat } & Mean & 3.46 & 2.93 \\
\hline & SD & 0.70 & 0.87 \\
\hline Sample Size & & 208 & 275 \\
\hline
\end{tabular}




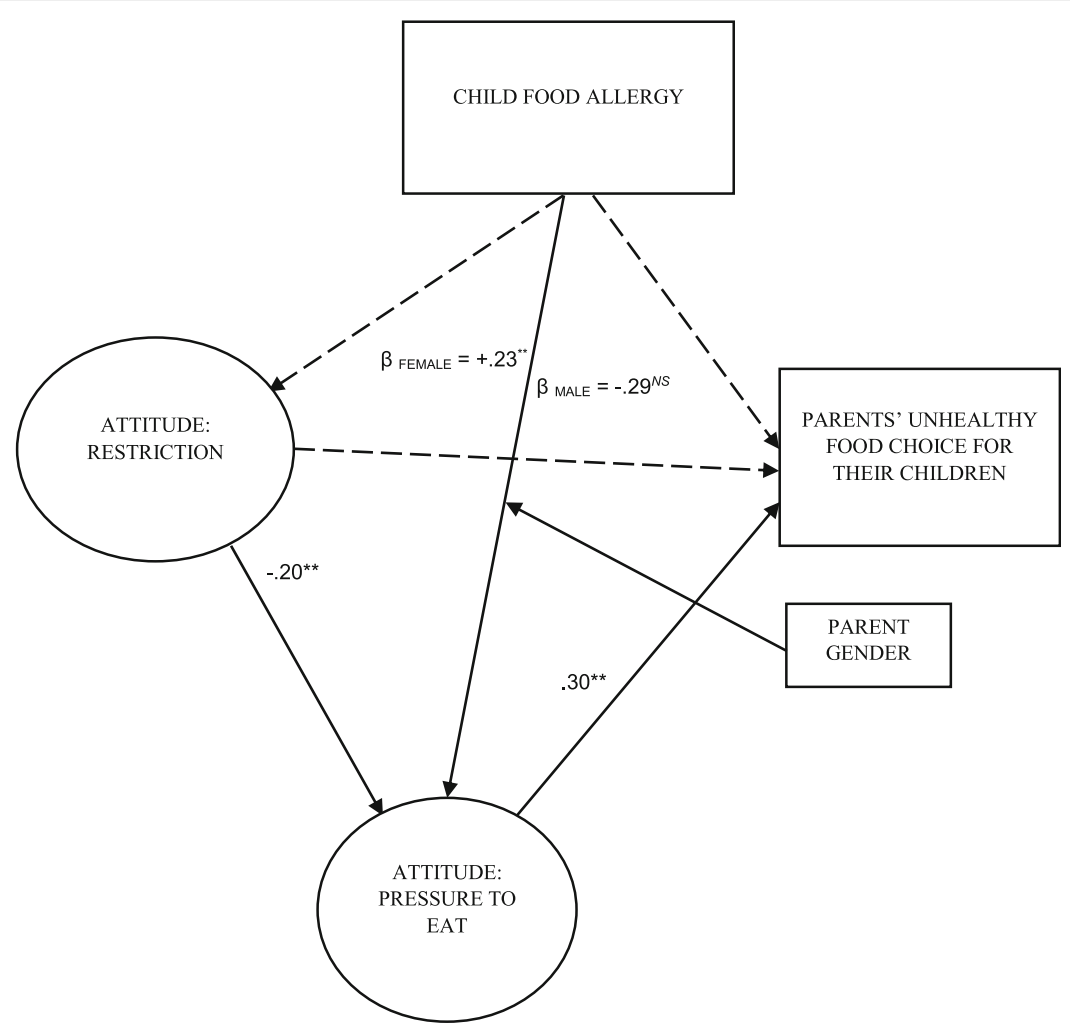

Fig. 2 Alternate model. Note. Ns denotes non-significant; ${ }^{* *} p<.01$; dashed arrows represent non-significant paths

negative effects of restriction on parental unhealthy food choice for their children.

To assess the invariance of the model concerning the different levels of parent's education and income, separate tests are also run for each of the two subgroups in parent's education (i.e., low educated and highly educated), gender (i.e., male and female) and household income (i.e., low and high), with the outcomes being invariant from that of analysis of the sample as a whole [8]. The invariant/equivalence analysis examines the non-equivalence between an unconstrained model, which hypothesises that the groups are causing different scores of the parameters when we apply the model to the observed data, and a set of constrained models, which presume that the groups are generating invariant scores of given sets of parameters when we apply the model to the data [8]. The unconstrained model, in our case, generated a substantial chi-square value, $\chi^{2}(6, N=$ $483)=19.76, p=.003$, for parent's gender as well as a non-substantial chi-square values regarding household income $\chi^{2}(6, N=483)=4.27, p=.641$, and parent's educational level $\chi^{2}(6, N=483)=8.03, p=.236$. Thus, we come to the conclusion that parent's gender, at least, moderates, one path in our hypothesised model. Further,

Table 2 Alternate model path analysis

\begin{tabular}{|c|c|c|c|}
\hline \multicolumn{3}{|l|}{ Path } & \multirow{2}{*}{$\frac{\text { Estimate } \beta}{-.20^{* *}}$} \\
\hline Restriction & $\rightarrow$ & Pressure to Eat & \\
\hline Child Food Allergy & $\rightarrow$ & Pressure to Eat & $.19^{* *}$ \\
\hline Pressure to Eat & $\rightarrow$ & Parental Unhealthy Food Choice for their Children & $30^{* *}$ \\
\hline \multicolumn{4}{|l|}{$X^{2} / d f=2.51<3$} \\
\hline \multicolumn{4}{|l|}{$\mathrm{CFI}=.958>.9$} \\
\hline \multicolumn{4}{|l|}{$\mathrm{TLI}=.933>.9$} \\
\hline \multicolumn{4}{|l|}{$\mathrm{SRMR}=.042<.08$} \\
\hline RMSEA $=.056<.08$ & & & \\
\hline
\end{tabular}


Table 3 Testing indirect effects

\begin{tabular}{llll}
\hline$\#$ & Mediation path & Mediation Estimate B & Mediation type \\
\hline 1 & Child food allergy $\rightarrow$ Pressure to eat $\rightarrow$ Parental unhealthy food choice & $.05^{* *}$ & Full \\
2 & Restriction $\rightarrow$ Pressure to eat $\rightarrow$ Parental unhealthy food choice & $-.02^{* *}$ & Full \\
\hline$* * P<01$ & & &
\end{tabular}

** $P<01$

in order to determine the moderated path(s), we make pairwise parameter comparisons [54]. Z score is determined based on the Bonferroni corrected level of statistical significance, which is equal to .02 [54]. Hence, we evaluate the substantiality of the pairwise parameter variations based on a $\mathrm{Z}$ score equal to 2.054. The findings demonstrate that only the link between child food allergy and pressure to eat is not invariant between fathers and mothers $(Z=3.279>2.054)$. Put it another way, only females, i.e., mothers, are more likely to put more feeding pressure on their food-allergic children $\left(\beta_{\text {mothers }}=\right.$ $.23, P<.01)$. Whilst, that situation is unlikely to happen $\left(\beta_{\text {Fathers }}=-.29, P>.05\right)$ amongst male parents (i.e., fathers). Based on these analyses (see Fig. 2), we decide that $\mathrm{H} 1, \mathrm{H} 3$, and $\mathrm{H} 4$ are partially valid. $\mathrm{H} 2$ is rejected.

\section{Discussion}

This study examined a number of relationships among the theoretically proposed set of variables and found partial support for $\mathrm{H} 1, \mathrm{H} 3$, and $\mathrm{H} 4$. That suggested that pressure to eat is the main direct predictor that links positively to (and explain the changes in) parental unhealthy food choices for their children. Further, the pressure to eat serves as a full mediator, transmitting the positive indirect effects of childhood food allergy on mothers' unhealthy food choices for their children. Furthermore, the pressure to eat was found to fully buffer the negative indirect impacts of food intake restriction on both fathers' and mothers' unhealthy food choices for their children. These findings are in line with previous research proposing the need for greater parental supervision regarding children' healthy eating choices [55]. However, in times of crisis and food shortages, such as during the 2020 coronavirus (covid-19) pandemic, parental supervision may be constrained by the difficulties in accessing appropriate food, e.g. gluten-free diet $[13,56]$. In addition to the empty shelves reported by Athas, CBS News [56] found that some parents experienced difficulties going out to shop due to the lockdown, and this places them at a more considerable disadvantage with regards to food purchases. This leads to some parents (particularly those on a low income with no means of transportation) diminished control over the diet of their children with allergies. This social category is generally the least prepared for times of pandemic [57]. Equally, protracted social isolation causes issues of weight gain and obesity $[2,16-18]$.

Interestingly, we found partial support for our $\mathrm{H} 4$, suggesting that mothers are more likely to be more engaged in pressure-to-eat behaviours towards their food-allergic children than fathers. This finding is in line with studies of mothers and fathers of children with a food allergy or even other health conditions (e.g., [20]). It may indicate to the propensity for many fathers and mothers to engage differently in child-related health care. In this regard, we argue that mothers seem to be keener to have their food-allergic children on a full stomach than fathers do. Such keenness appears to be embodied with making children with food allergy eat more of their 'free from' food (i.e., free from relevant allergens). Thus, these children would not feel the desire to eat other non-especially-prepared food, that might contain allergens, in the absence of the parents.

Our results indicate that more efforts are required to educate parents about their children's healthy food decisions. The study also suggests that during a crisis period such as the current on-going covid-19 pandemic, families with children with allergies need more information and support in order to maintain certain normality in the diet of their children to curb anxiety and poor health. Such support will give parents the confidence to allergy reactions more effectively [14] and improve their own mental wellbeing [15]. While governments and medical practitioners are determined to combat the increasing prevalence of childhood obesity, the results of this research indicate that they are fighting an uphill battle. Not only is compulsive and unhealthy eating prevalent in society; it has become an epidemic. Thus, health and nutritional information of the meals should be communicated to parents more effectively, i.e., in a simple, understandable and accessible way and using a wide variety of communication channels to reach all social groups. Future research can tackle the need for preventive actions rather than a cure. In particular, future researchers can investigate how marketing activities could aid parents to prevent obesity in children rather than seeking a cure after the epidemic has occurred.

A potential role for the public policy regarding parental healthier food decisions for their children could be implemented at the individual level (i.e., the parents as customers) through taxing unhealthy meals at fast-food restaurants. Taking such a measure may entail taxing foods high in calories, saturated fat, sodium, and sugar, or, in other words, taxing the causes of dietary obesity as that would reduce the affordability of unhealthy foods [58]. However, that should be done with caution since such an approach is likely to be regressive, i.e., poor 
people would pay a higher share of their income taxes than rich people would [59]. The implementation of a food tax is not a new policy on public health for unhealthy food products. Finland, France and Hungary alone implemented a new tax on soft drinks in 2011 and 2012. Similarly, there has been a 'sweet' tax imposed on soft drinks in the city of Berkeley (California) [60] and the city of Philadelphia (Pennsylvania) in the USA [61]. In parallel, Denmark introduced a new tax on foods containing more than $2.5 \%$ of saturated fat content [59]. In this regard, many researchers have suggested that introducing such taxes has resulted in significant improvements in people's dietary intake [62].

While we conducted this study in two Northern American countries of the United States and Canada, the results should be of sufficient external validity in other states within both countries. The data collected from two small regions within the US and Canada are generalisable to regions beyond those sampled in the present study, considering the widespread nature of childhood obesity [63]. However, further replications should be performed to validate our theoretical model either in developed countries or other contexts. Such studies would educate health care professionals, governments, and parents of any variances between cultures, ethnic groups or social classes regarding making unhealthy food choices for children [64].

The use of self-reporting data, which, can generate bias in the responses obtained. It is because this sort of data implicitly suggests that the participants have the same understanding or interpretation of the questioning [65]. Some researchers criticise the use of the crosssectional design in concluding causal relationships. Nonetheless, findings generated from a cross-sectional study can still be regarded as interpretable and valid as long as they are conducted on a sound theoretical basis [66]. Since there is a limited theoretical basis, the conclusions about possible causality of the relationships studied in this research, however, carrying out future research to assess the validity of the existing model using a longitudinal design would be significantly endorsed.

Furthermore, the inclusion of objective assessments of variables that could relate to childhood obesity, e.g., Body Mass Index (BMI) would be highly endorsed while either replicating our study or generating a new model. It is worth noting that such variables could further moderate the relationships amongst the variables under investigation. For example, parental attitudes towards obesity may predict the child's weight status. Additionally, we built our methodology on a set of specific criteria to assess the healthiness of meal choice. The conditions were based on calories, sodium, and fat as $\% \mathrm{DV}$ [51]. As a result, a meal judged as healthy by criteria other than those utilised in this study can be decided unhealthy against the criteria we adopted in this study. Thus, we suggest that future research replicates our study alongside adopting more inclusive criteria (or different ones) to assess meal healthiness.

The pressure to eat has been linked to increased maternal concern about a child being 'underweight' [67], as well as children's food fussiness [68], and lower Body Mass Index (BMI) percentile scores in children [41]. All of which could be considered as variables of interest in future studies to develop more sophisticated models that would advance our knowledge of parental food choice. While our study models a path from childhood allergy to unhealthy food choices via attitudes, we conceptualised parent's 'gender' as a moderating variable rather than an exclusion criterion, which creates avenues for future investigations.

Further research is advised to assess what we would call 'parent-child meal consultation' could affect parental more democratic choices of healthy food for their children, especially those with food allergy. Finally, the approach of using a fast-food menu, which would offer limited healthy options, can bias the responses and data collected. It would add to the existing knowledge base if a similar study could capture the differences between parents who frequent fast food places against those who only order there on occasion, to gauge the degree of impact on food choices. Future research is encouraged to help understand choices based on interest, taste, preference, healthfulness, allergen avoidance, and food group avoidance (e.g., vegetarians). There has been evidence of the role of child gender (though not assessed within the scope of our study) in eating behaviour and parent-child dynamics [69]. Thus, to develop a full picture of parental food choices, additional studies will be needed that child gender would be considered as a covariate.

\section{Conclusion}

We investigated a theoretically proposed conceptual model predicting parental unhealthy food choices. We found that pressure to eat, positively predict parental unhealthy food choices for their children. Additionally, it transmits the childhood food allergy indirect effects on mothers' unhealthy food choices for their children. It makes such poor food selections more likely in case of the presence of childhood allergy. Parental engagement in pressure to eat behaviour was found to play another mediating role. It blocks the chances of engaging in healthy parental food choices because of relating to fathers' and mothers' tendency to set restrictions on their children's food intake. The paper contributes to the literature on food allergies among children and the marginalisation of families with allergies. Our explorative model is a first of its kind and highlights the complex relationships between the variables under consideration. 
Though the data collection precedes the covid-19 pandemic, our findings are relevant to the pandemic era because if in ordinary time families with allergies face significant challenges for making adequate food choices, then crisis periods such as the covid-19 pandemic could exacerbate the difficulties for those families. The paper, therefore, bears unique significance in consequence of the critical period in which it took place, i.e. the global coronavirus (Covid-19) pandemic as it draws the attention of policymakers to the vulnerability of families with allergies and how should also be prioritised in crisis times.

\section{Abbreviations \\ StatCan: Canadian Community Health Survey; Covid-19: Coronavirus pandemic}

\section{Acknowledgements}

Not applicable.

\section{Authors' contributions}

ABM: Wrote $10 \%$ of the background $+100 \%$ (methods \& research design + conceptual model \& hypotheses + data analysis + results) $+30 \%$ of the discussion + Collected 25\% of the data. DHP: Wrote 30\% background $+20 \%$ of the discussion. LF: Wrote $20 \%$ background $+20 \%$ of the discussion. DN: Collected $50 \%$ of the data + Wrote $20 \%$ background $+10 \%$ of the discussion. NG: Wrote $20 \%$ background $+20 \%$ of the discussion + Collected $25 \%$ of the data. All authors reviewed and commented on subsequent drafts of the manuscript. The author(s) read and approved the final manuscript.

\section{Funding}

No funding was received for this particular research.

\section{Availability of data and materials}

The data used in this study will not be available due to confidentiality issues.

\section{Ethics approval and consent to participate}

Our research received ethics approvals from St. John's University, USA and Crandall University, Canada. Written consent forms were obtained from the participants.

\section{Consent for publication}

Not applicable.

\section{Competing interests}

The authors declare no conflicts of interest in this study.

\section{Author details}

${ }^{1}$ University of Wales Trinity Saint David, London, UK. ${ }^{2}$ Crandall University, Moncton, Canada. ${ }^{3}$ University of Lincoln, Lincoln, UK. ${ }^{4}$ St. John's University, New York, USA. ${ }^{5}$ University of Illinois at Chicago, Chicago, IL, USA. ${ }^{6}$ Monash University, Melbourne, Victoria, Australia.

Received: 22 May 2020 Accepted: 17 September 2020

Published online: 25 September 2020

\section{References}

1. Birch LL, Fisher JO, Grimm-Thomas K, Markey CN, Sawyer R, Johnson SL. Confirmatory factor analysis of the child feeding questionnaire: a measure of parental attitudes, beliefs and practices about child feeding and obesity proneness. Appetite. 2001;36:201-10.

2. Chang W, Hillier AE, Mehta NK. Neighborhood racial isolation. Disord Obesity Soc Forces. 2009;87(4):2063-92.

3. Taillie LS. Who's cooking? Trends in US home food preparation by gender, education, and race/ethnicity from 2003 to 2016. Nutr J. 2018;17(1):41.

4. Nørgaard MK, Brunsø K. Family conflicts and conflict resolution regarding food choices. J Consum Behav. 2011;10:141-51.

5. StatCan. Percentage of Canadian adolescents that are overweight or obese based on BMI from 2005 to 2018: Statista; 2020.
6. Hales CM, Carroll MD, Fryar CD, Ogden CL. Prevalence of obesity among adults and youth: United States, 2015-2016. NCHS Data Brief, vol. 288; 2017.

7. Wang Y, Lim H. The global childhood obesity epidemic and the association between socio-economic status and childhood obesity: Taylor \& Francis; 2012.

8. Mahmoud AB, Grigoriou N. Modelling parents' unhealthy food choices for their children: the moderating role of child food allergy and implications for health policy. J Fam Stud. 2019:1-19.

9. Grace-Farfaglia P, Peters SL. Parental attitudes toward childhood obesity: risky business. Integrative Food. Nutr Metab. 2016;3:2.

10. Chinn S, Rona RJ. Prevalence and trends in overweight and obesity in three cross sectional studies of British children, 1974-94. BMJ. 2001;322(7277):24-6.

11. Birch LL. Development of food preferences. Annu Rev Nutr. 1999;19(1):41-62.

12. Wardle J, Sanderson S, Guthrie CA, Rapoport L, Plomin R. Parental feeding style and the inter-generational transmission of obesity risk. Obes Res. 2002; 10(6):453-62.

13. Families With Food Allergies Struggle With Bare Shelves [https://www. nytimes.com/2020/04/07/health/coronavirus-food-allergies.html].

14. Chooniedass R, Temple B, Martin D, Becker A. A qualitative study exploring parents' experiences with epinephrine use for their child's anaphylactic reaction. Clin Translational Allergy. 2018;8(1):1-9.

15. Here's What Parents Of Young Kids With Food Allergies Don't Need: More Guilt [https://www.cbc.ca/parents/learning/view/heres-what-parents-ofyoung-kids-with-food-allergies-dont-need-more-guilt].

16. How to stop binge eating during lockdown [https://www.telegraph.co.uk/ health-fitness/nutrition/beat-erratic-eating-lockdown/].

17. Clark Bryan D, Macdonald P, Ambwani S, Cardi V, Rowlands K, Willmott D, Treasure J. Exploring the ways in which COVID-19 and lockdown has affected the lives of adult patients with anorexia nervosa and their carers. Eur Eating Dis Rev. 2020; n/a(n/a).

18. Termorshuizen JD, Watson HJ, Thornton LM, Borg S, Flatt RE, MacDermod CM, Harper LE, van Furth EF, Peat CM, Bulik CM. Early Impact of COVID-19 on Individuals with Eating Disorders: A survey of 1000 Individuals in the United States and the Netherlands. medRxiv 2020. 2020;2005(2028): 20116301.

19. Miller D, Johnson W, Miller M, Miller J, Sutin AR. Caregiver perceptions of childhood weight: demographic moderators and correlates. Child Care Health Dev. 2016:42(3):370-4.

20. Hoehn JL, Dahlquist LM, Hahn AL, Bollinger ME. Parents of children with food allergy: gender differences in perceived impact and perceived food allergy severity. J Pediatr Psychol. 2017:42(2):186-97.

21. Gupta R, Holdford D, Bilaver L, Dyer A, Holl JL, Meltzer D. The economic impact of childhood food allergy in the United States. JAMA Pediatr. 2013; 167(11):1026-31

22. Greenhawt M, Shaker M, Stukus DR, Fleischer DM, Hourihane J, Tang M, Abrams EM, Wang J, Bingemann TA, Chan ES, et al. Managing Food Allergy in Schools During the COVID-19 Pandemic. J Allergy Clin Immunol Pract. 2020;\$2213-2198(2220):30724-8.

23. Cannon HE. The economic impact of peanut allergies. Am J Manag Care. 2018:24(19 Suppl):S428-s433.

24. Christie L, Hine RJ, Parker JG, Burks W. Food allergies in children affect nutrient intake and growth. J Am Diet Assoc. 2002;102(11):1648-51.

25. Cummings AJ, Knibb RC, King RM, Lucas JS. The psychosocial impact of food allergy and food hypersensitivity in children, adolescents and their families: a review. Allergy. 2010;65(8):933-45.

26. FDA approves first peanut allergy drug for children [https://www. aappublications.org/news/2020/02/05/peanutallergy020520].

27. Vickers B, Boyle RJ, Umasunthar T, Smith JG, Hodes M. Therapy competence in delivering a brief cognitive behavioural therapy intervention to reduce maternal anxiety associated with child food allergy. J Child Health Care. 2019;23(3):446-57.

28. DunnGalvin A, Dubois A, Flokstra-de Blok B, H JO"B. The effects of food allergy on quality of life. In: Ebisawa M, Ballmer-Weber BK, Vieths S, Wood RA, editors. Food Allergy: Molecular Basis and Clinical Practice. Volume 101: Karger Publishers; 2015. p. 235-52.

29. Lau GY, Patel N, Umasunthar T, Gore C, Warner JO, Hanna H, Phillips K, Mohd Zaki A, Hodes M, Boyle RJ. Anxiety and stress in mothers of foodallergic children. Pediatr Allergy Immunol. 2014;25(3):236-42.

30. Fiocchi A, Brozek J, Schünemann H, Bahna SL, Von Berg A, Beyer K, Bozzola M, Bradsher J, Compalati E, Ebisawa M, et al. World allergy organization (WAO) diagnosis and rationale for action against cow's milk allergy (DRAC MA) guidelines. World Allergy Organization Journal. 2010;3(4):57. 
31. Wu YP, Franciosi JP, Rothenberg ME, Hommel KA. Behavioral feeding problems and parenting stress in eosinophilic gastrointestinal disorders in children. Pediatr Allergy Immunol. 2012;23(8):730-5.

32. Calsbeek H, Rijken M, Bekkers MJ, Kerssens JJ, Dekker J, van Berge Henegouwen GP. Social position of adolescents with chronic digestive disorders. Eur J Gastroenterol Hepatol. 2002;14(5):543-9.

33. Visness CM, London SJ, Daniels JL, Kaufman JS, Yeatts KB, Siega-Riz AM, Liu $\mathrm{AH}$, Calatroni A, Zeldin DC. Association of obesity with lgE levels and allergy symptoms in children and adolescents: results from the National Health and Nutrition Examination Survey 2005-2006. J Allergy Clin Immunol. 2009; 123(5):1163-9 1169 e1161-1164.

34. Noimark L, Gardner J, Warner JO. Parents' attitudes when purchasing products for children with nut allergy: a UK perspective. Pediatr Allergy Immunol. 2009;20(5):500-4.

35. McAllister EJ, Dhurandhar NV, Keith SW, Aronne LJ, Barger J, Baskin M, Benca RM, Biggio J, Boggiano MM, Eisenmann JC, et al. Ten putative contributors to the obesity epidemic. Crit Rev Food Sci Nutr. 2009;49(10):868-913.

36. Shin $\mathrm{H}$, Baek S. Factors on educational outcome for obesity prevention in female adolesecents in Korea. Int J Pediatr Endocrinol. 2013:2013(S1):P103.

37. Obesity Linked to Severe Coronavirus Disease, Especially for Younger Patients [https://www.nytimes.com/2020/04/16/health/coronavirus-obesityhigher-risk.html].

38. Clark HR, Goyder E, Bissell P, Blank L, Peters J. How do parents' child-feeding behaviours influence child weight? Implications for childhood obesity policy. J Public Health. 2007;29(2):132-41.

39. Bourcier E, Bowen DJ, Meischke H, Moinpour C. Evaluation of strategies used by family food preparers to influence healthy eating. Appetite. 2003; 41(3):265-72.

40. Birch LL, Ventura AK. Preventing childhood obesity: what works? Int J Obes. 2009:33(S1):S74.

41. Galloway AT, Fiorito LM, Francis LA, Birch LL. 'Finish your soup': counterproductive effects of pressuring children to eat on intake and affect. Appetite. 2006;46(3):318-23.

42. Kumanyika SK. Environmental influences on childhood obesity: ethnic and cultural influences in context. Physiol Behav. 2008;94(1):61-70.

43. Shloim N, Edelson LR, Martin N, Hetherington MM. Parenting styles, feeding styles, feeding practices, and weight status in 4-12 year-old children: a systematic review of the literature. Front Psychol. 2015;6:1849.

44. Moore LC, Harris CV, Bradlyn AS. Exploring the relationship between parental concern and the management of childhood obesity. Matern Child Health J. 2012;16(4):902-8.

45. Niklas KJ, Enquist BJ. Invariant scaling relationships for interspecific plant biomass production rates and body size. Proc Natl Acad Sci U S A. 2001;98(5):2922-7.

46. Junk Food Nation: How Parents Are Ruining Kids' Health [https://www. livescience.com/14280-parents-feed-kids-junk.html].

47. I understand why parents feed their kids unhealthy foods: It's not because parents don't know enough about nutrition! [https://www.psychologytoday. com/ca/blog/the-art-science-teaching-kids-eat-right/201409/i-understandwhy-parents-feed-their-kids].

48. Savage JS, Fisher JO, Birch LL. Parental influence on eating behavior: conception to adolescence. J Law Med Ethics. 2007:35(1):22-34.

49. Baron RM, Kenny DA. The moderator-mediator variable distinction in social psychological research: conceptual, strategic, and statistical considerations. J Pers Soc Psychol. 1986;51(6):1173.

50. Brand value of the 10 most valuable fast food brands worldwide in 2018 (in million U.S. dollars) [https://www.statista.com/statistics/273057/value-of-themost-valuable-fast-food-brands-worldwide/].

51. Board of Supervisors. Setting Nutritional Standards for Restaurant Food Sold Accompanied by Toys or other Youth Focused Incentive Items. In: Ordinance amending Article 8 of the San Francisco Health Code Francisco CaCoS, vol. Ordinance No. 290-10 San Francisco: City and County of San Francisco; 2010.

52. Meyers L, Gamst GC, Guarino AJ. Applied multivariate research: design and interpretation. Thousand Oaks: SAGE Publications, Inc.; 2017.

53. Mahmoud AB, Sitladin M, Tehseen S, Fuxman L, Reisel WD, Purkayastha $H$, Grigoriou N. Job Satisfaction As A Mediator Between Performance Appraisal Effectiveness And Organisational Outcomes In The Caribbean. In: British Academy of Management: 2020; Manchester: Alliance Manchester business School I University of Manchester BAM; 2020.

54. Mahmoud AB, Grigoriou N, Fuxman L, Hack-Polay D, Mahmoud FB, Yafi E, Tehseen S. Email is evil! J Res Interact Mark. 2019;13(2):227-48.
55. Brown R, Ogden J. Children's eating attitudes and behavior: a study of the modelling and control theories of parental influence. Health Educ Res. 2004 19(3):261-71.

56. Tips for safe grocery shopping during coronavirus pandemic [https://www. cbsnews.com/news/coronavirus-pandemic-safe-grocery-shopping-tips/].

57. Shorette K. Review of unprepared: Global Health in a time of emergency. Social Forces. 2018;96(4):e7.

58. Mytton OT, Clarke D, Rayner M. Taxing unhealthy food and drinks to improve health. BMJ. 2012;344(may15 2):e2931.

59. Crawford I, Leicester A, Windmeijer F. The 'fat tax'. London: The Institute of Fiscal Studies; 2004.

60. Falbe J, Thompson HR, Becker CM, Rojas N, McCulloch CE, Madsen KA. Impact of the Berkeley excise tax on sugar-sweetened beverage consumption. Am J Public Health. 2016;106(10):1865-71.

61. Byrne P, Chulkov D, Nizovtsev D. Philadelphia's taxing decision: pros and cons of a "soda tax". CASE J. 2019.

62. Dharmasena S, Capps O. Intended and unintended consequences of a proposed national tax on sugar-sweetened beverages to combat the US obesity problem. Health Econ. 2012;21(6):669-94.

63. James PT, Leach R, Kalamara E, Shayeghi M. The worldwide obesity epidemic. Obes Res. 2001;9(Suppl 4 S11):228S-33S.

64. O'Dea JA. Gender, ethnicity, culture and social class influences on childhood obesity among Australian schoolchildren: implications for treatment, prevention and community education. Health Social Care Community. 2008; 16(3):282-90.

65. Kesmodel US. Information bias in epidemiological studies with a special focus on obstetrics and gynecology. Acta Obstet Gynecol Scand. 2018;97(4):417-23.

66. Tharenou P, Donohue R, Cooper B. Management research methods. Cambridge: Cambridge University Press; 2007.

67. Gregory JE, Paxton SJ, Brozovic AM. Pressure to eat and restriction are associated with child eating behaviours and maternal concern about child weight, but not child body mass index, in 2-to 4-year-old children. Appetite. 2010:54(3):550-6.

68. Jansen PW, de Barse LM, Jaddoe WW, Verhulst FC, Franco OH, Tiemeier H. Bidirectional associations between child fussy eating and parents' pressure to eat: who influences whom? Physiol Behav. 2017;176:101-6.

69. Banna J, O'Driscoll J, Boushey CJ, Auld G, Olson B, Cluskey M, Ballejos ME, Bruhn C, Misner S, Reicks M, et al. Parent and household influences on calcium intake among early adolescents. BMC Public Health. 2018;18(1):1390.

\section{Publisher's Note}

Springer Nature remains neutral with regard to jurisdictional claims in published maps and institutional affiliations.

Ready to submit your research? Choose BMC and benefit from:

- fast, convenient online submission

- thorough peer review by experienced researchers in your field

- rapid publication on acceptance

- support for research data, including large and complex data types

- gold Open Access which fosters wider collaboration and increased citations

- maximum visibility for your research: over $100 \mathrm{M}$ website views per year

At BMC, research is always in progress.

Learn more biomedcentral.com/submissions 